Table I. Physical Properties of Pillared Layered Oxides

\begin{tabular}{|c|c|c|c|c|c|c|}
\hline \multirow[b]{2}{*}{ layered precursor } & \multicolumn{2}{|c|}{ basal $d$ spacing, $\AA$} & \multicolumn{2}{|c|}{ surface area, $\mathrm{m}^{2} / \mathrm{g}$} & \multicolumn{2}{|c|}{$\begin{array}{l}\text { cyclohexane } \\
\text { adsorptn, }^{a} \text { wt } \%\end{array}$} \\
\hline & initial $^{b}$ & $\overline{\text { final }^{c}}$ & initial & $\overline{\text { final }}$ & initial & final \\
\hline $\begin{array}{l}\text { titanates } \mathrm{Na}_{2} \mathrm{Ti}_{3} \mathrm{O}_{7} \\
\text { Metal titanate } \mathrm{Cs}_{0.7}\left(\mathrm{Ni}_{0.35} \mathrm{Ti}_{1.65}\right) \mathrm{O}_{4} \\
\text { magadiite } \\
\text { kenyaite }\end{array}$ & $\begin{array}{r}8.4 \\
8.4 \\
11.5 \\
17.5\end{array}$ & $\begin{array}{l}20 \\
22 \\
33 \\
36\end{array}$ & $\begin{array}{l}<5 \\
<5 \\
<20 \\
\leq 20\end{array}$ & $\begin{array}{l}280 \\
300 \\
530 \\
600\end{array}$ & $\begin{array}{l}<1 \\
<1 \\
<2 \\
<5\end{array}$ & $\begin{array}{r}9 \\
10 \\
14 \\
21\end{array}$ \\
\hline
\end{tabular}

${ }^{a}$ At $25^{\circ} \mathrm{C}, 40$ Torr. ${ }^{b}$ Dehydrated phase. ${ }^{c}$ Swollen with octylammonium, pillared with silica.

Table II. Properties of Pillared Alkali Titanates with Varying $d$ spacings

\begin{tabular}{lccc}
\hline \multicolumn{1}{c}{ swelling agent } & $\begin{array}{c}\text { surface } \\
\text { area, } \\
\mathrm{m}^{2} / \mathrm{g}\end{array}$ & $\begin{array}{c}\text { increase in } \\
d \text { spacing, }{ }^{a} \AA\end{array}$ & $\begin{array}{c}\text { cyclohexane } \\
\text { adsorptn, wt \% }\end{array}$ \\
\hline starting material $\mathrm{Na}_{2} \mathrm{Ti}_{3} \mathrm{O}_{7}$ & $<5$ & $<1$ & $<1$ \\
propylammonium & 50 & $2-3$ & $<3$ \\
hexylammonium & 200 & 9 & 6 \\
octylammonium & 280 & 12 & 9 \\
dodecylammonium & 470 & 21 & 16 \\
\hline
\end{tabular}

${ }^{a}$ The increase in $d$ spacing is calculated by the formula $d_{001}$ (pillared) $-d_{001}$ (layered phase), where $d_{001}$ (layered phase) $=8.4 \AA$.

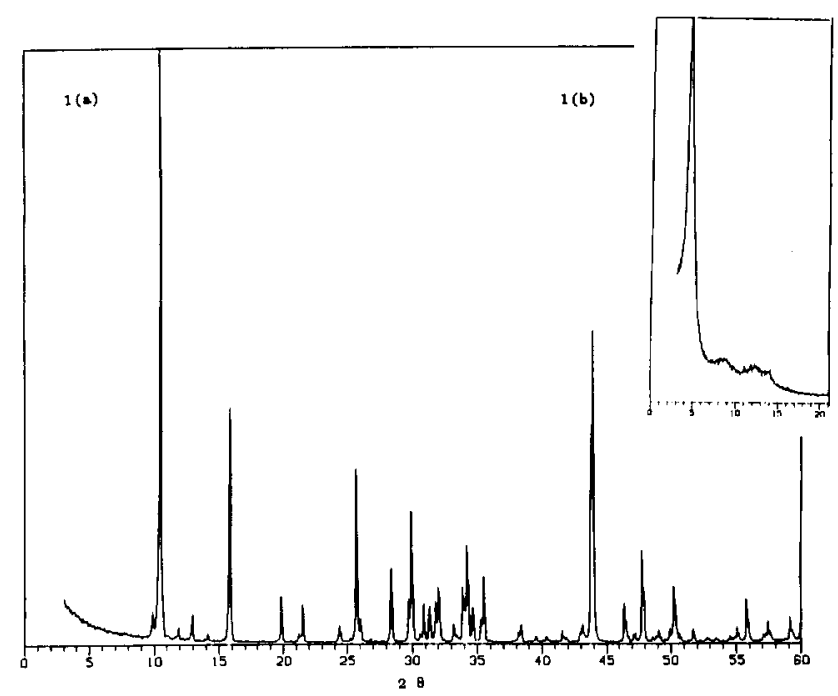

Figure 1. X-ray diffraction pattern of sodium titanate (1a) and silicapillared sodium titanate $(\mathbf{1 b})$.

$\mathrm{A}_{x}[\mathrm{MTi}]_{2} \mathrm{O}_{4},{ }^{12}$ and layered silicates such as magadiite, $\mathrm{Na}_{2} \mathrm{Si}_{7} \mathrm{O}_{15}$, and kenyaite, $\mathrm{K}_{2} \mathrm{Si}_{14} \mathrm{O}_{29}$. Table I outlines the starting materials and relevant physical properties of the porous silica-pillared products.

Evidence for the creation of pillared, microporous products follows. First, X-ray diffraction patterns (Figure 1) of a dense, layered titanate, $\mathrm{Na}_{2} \mathrm{Ti}_{3} \mathrm{O}_{7}(\mathbf{1 a})$, and its silica-pillard product ${ }^{13}$ (1b) after calcination at $538^{\circ} \mathrm{C}$ indicate a large increase in basal spacing $(\sim 12 \AA)$. Secondly, this silica-pillared titanate, containing only $23 \mathrm{wt} \%$ silica, shows an increase in surface area from $<5$ $\mathrm{m}^{2} / \mathrm{g}$ in the starting $\mathrm{Na}_{2} \mathrm{Ti}_{3} \mathrm{O}_{7}$ to $280 \mathrm{~m}^{2} / \mathrm{g}$ in the product. SEM photographs do not reveal significant amounts of amorphous silica external to the titanate crystallites. Also, a dense silica phase completely filling the interlayer region would not give rise to the observed high surface areas. Finally, this product adsorbs $9 \mathrm{wt}$ $\%$ cyclohexane (Table I), characteristic of microporous solids such as zeolites.

This novel pillaring technique allows for tailoring of pore sizes as exemplified in Table II for a series of pillared titanates. As

(11) Anderson, S.; Wadsley, A. D. Acta Crystallogr. 1961, 14, 1245. (12) Reid, A. F.; Mumme, W. G.; Wadsley, A. D. Acta Crystallogr. 1968, B24, 1228. Groult, D.: Mercey, C.; Raveau, B. J. Solid State Chem. 1980, $32,289$.

(13) The X-ray diffraction pattern of the calcined silica-pillared product is very similar to that of its organoammonium precursor. the alkyl chain length of the preswelling organic is increased, the observed $d$ spacing, reflective of the pore size, also increases. Surface area and cyclohexane adsorption also increase with increasing interlayer separation. These examples illustrate preparation of stable pillared products with interlayer separations of 3-20 $\AA$, determined by the size of the swelling agent. By careful choice of the organic preswelling agent, an even broader range of pore sizes are accessible. Thus, this new procedure not only allows for pillaring of diverse layer compositions but also permits the synthesis of materials with a wide range of pore sizes.

The ability to controllably modify chemical composition as well as pore size provides the flexibility to tailor catalysts for specialized end uses, and the catalytic potential of these materials is actively being explored.

\section{NMR Determination of the Bond Lengths in $\mathrm{C}_{60}$}

C. S. Yannoni, ${ }^{*}$ P. P. Bernier, ${ }^{\dagger}$ D. S. Bethune, G. Meijer, ${ }^{\ddagger}$ and J. R. Salem

\author{
IBM Research Division \\ Almaden Research Center \\ San Jose, California \\ Received February 7, 1991
}

Several years ago, the idea that 60 carbon atoms could form a molecule with icosahedral symmetry was conceived as a purely theoretical possibility. ${ }^{1}$ Subsequently, mass spectrometric evidence indicated that microscopic quantities of this fascinating molecule could be produced in cluster beam experiments. ${ }^{2}$ More recently, success in generating $\mathrm{C}_{60}$ molecules in macroscopic amounts ${ }^{3}$ has stimulated intense interest and activity, and a number of spectroscopic studies of $\mathrm{C}_{60}$ have confirmed that the molecular symmetry is indeed icosahedral $\left(I_{h}\right){ }^{4}$ We have carried out solid-state ${ }^{13} \mathrm{C}$ NMR experiments which showed that although $\mathrm{C}_{60}$ reorients rapidly in the solid state at ambient temperatures, the motion can be slowed sufficiently by lowering the temperature that a measurement of the ${ }^{13} \mathrm{C}$ chemical shift anisotropy can be made. ${ }^{5}$ The observed line shapes also indicate that the reorientational dynamics for $\mathrm{C}_{60}$ is not uniform throughout the sample, which contained $\sim 10 \% \mathrm{C}_{70}{ }^{5,6}$

Although the icosahedral symmetry of $\mathrm{C}_{60}$ is now established with reasonable certainty, the detailed electronic and geometric structures of this molecule are still of considerable interest. Many

\footnotetext{
† Present address: GDPC.USTL, 34095 Montpelier, France.

'Present address: Department of Molecular and Laser Physics, Catholic University of Nijmegen, Toernooiveld, 6525 ED Nijmegen, The Netherlands.

(1) For this history, see: Kroto, H. W. Science 1988, 242, 1139.

(2) Heath, J. R. Spectroscopy 1990, 5, 36. Curl, R. F.; Smalley, R. E Science 1988, 242, 1017.

(3) Krätschmer, W.; Lamb, L. D.; Fostiropoulos, K.; Huffman, D. R. Nature 1990, 347, 354.

(4) Johnson, R. D.; Meijer, G.; Bethune, D. S. J. Am. Chem. Soc. 1990 112, 8983. Taylor, R.; Hare, J. P.; Abdul-Sada, A. K.; Kroto, H. W. Chem Commun. 1990, 20, 1423 . Krätschmer, W.; Fostiropoulos, K.; Huffman, D. R. Chem. Phys. Lett. 1990, 170, 167. Bethune, D. S.; Meijer, G.; Tang, W. C.; Rosen, H. J. Chem. Phys. Lett. 1990, 174, 219. Bethune, D. S.; Meijer, G.; Tang, W. C.; Rosen, H. J.; Golden, W. G.; Seki, H.; Brown, C. A.; DeVries, M. S. Chem. Phys, Lett. In press.

(5) Yannoni, C. S.; Johnson, R. D.; Meijer, G.; Bethune, D. S.; Salem, J. R. J. Phys. Chem. 1991, 95, 9 .

(6) The same inhomogeneity in dynamics appears to hold in a sample of pure $C_{60}$; see: Tycko, R.; Haddon, R. C.; Dabbagh, G.; Glarum, S. H.; Douglass, D. C.; Mujsce, A. M. J. Phys. Chem. 1991, 95, 518.
} 


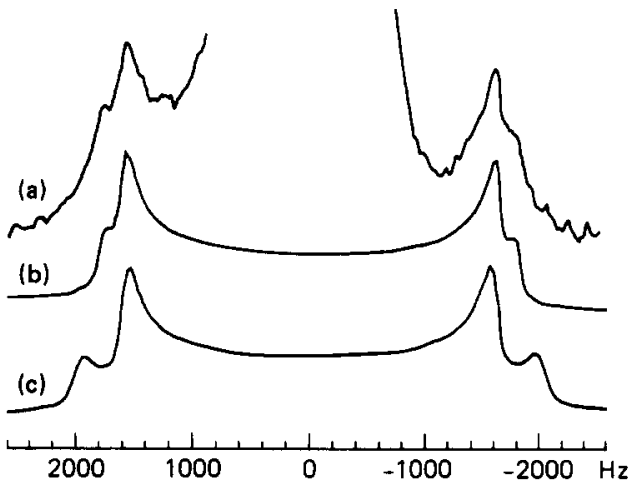

Figure 1. (a) Fourier transform of the ${ }^{13} \mathrm{C}$ signal obtained in a CarrPurcell Meiboom-Gill sequence carried out on ${ }^{13} \mathrm{C}$-enriched $\mathrm{C}_{60}$ at $77 \mathrm{~K}$. The intense center line has been cropped for clarity (vide infra). The time domain signal was obtained by co-adding 60000 transients with a 10-s delay between pulse sequences. (b) Simulation of two Pake doublets with carbon-carbon bond lengths of 1.45 and $1.40 \AA \AA$; (c) as in (b), but with bond lengths of 1.451 and $1.345 \AA$.

electronic structure calculations have been carried out, giving predictions for the optical spectrum and geometry, and in particular the bond lengths, of $\mathrm{C}_{60 .}{ }^{7}$ To date, the most detailed geometric data have been provided by X-ray diffraction ${ }^{3}$ and by STM imaging. ${ }^{8}$ Both of these techniques indicate that the distance between molecular centers in the solid state is $\sim 10 \AA$, but neither gives more detail because of rapid molecular reorientation. 5,6 In the case of X-ray diffraction, static and/or dynamic disorder may contribute to the failure to determine the internal molecular structure.

In this communication we report a direct ${ }^{13} \mathrm{C}$ NMR measurement of two carbon-carbon bond lengths in $\mathrm{C}_{60}{ }^{9}$ using the Carr-Purcell sequence ${ }^{10}$ which has recently been quantified for measuring internuclear distances in orientationally disordered materials. ${ }^{11}$

The bond lengths are obtained from a measurement of ${ }^{13} \mathrm{C}-{ }^{13} \mathrm{C}$ magnetic dipolar coupling which depends on the inverse cube of the distance between nuclei. ${ }^{12}$ Since the ${ }^{13} \mathrm{C}$ isotope is only $1.1 \%$ naturally abundant, it is necessary to enrich the sample in ${ }^{13} \mathrm{C}$ to observe this coupling. Samples of $\mathrm{C}_{60}$ enriched in ${ }^{13} \mathrm{C}$ were prepared by toluene extraction of soot generated by arc heating graphite in 100 Torr of $\mathrm{He}$. The electrodes were fabricated by coring out graphite rods and packing them with ${ }^{13} \mathrm{C}$-enriched amorphous carbon. ${ }^{13}$ Solution NMR indicated that the sample was enriched to $\sim 6 \%{ }^{13} \mathrm{C}$. Mass spectrometry and solution NMR further showed that the sample consisted of $\mathrm{C}_{60}$ and $\mathrm{C}_{70}$ in a ratio of $\sim 6: 1$.

To measure the ${ }^{13} \mathrm{C}-{ }^{13} \mathrm{C}$ dipolar coupling, we have used the Carr-Purcell sequence ${ }^{10}$ to selectively remove broadening due to the chemical shift anisotropy while retaining the dipolar coupling. " The sequence, which consists of a single resonant $\pi / 2$ pulse followed by a train of $\pi$ pulses, produces a train of spin echoes..$^{15}$ The amplitude of these echoes, captured in receiver windows between pulses, constitutes the transient NMR signal and is stored in a computer for coherent averaging. ${ }^{11,16}$ Dipolar coupling is

(7) For a review of bond lengths calculated for $\mathrm{C}_{60}$ see: Feng, J.; Li, J.; Wang, A.; Zerner, M. C. Intl. J. Quantum Chem. 1990, 37, 599.

(8) Wilson, R. J.; Meijer, G.: Bethune, D. S.; Johnson, R. D.: Chambliss, D. D.; DeVries, M. S.; Hunziker, H. H.; Wendt, H. R. Nature 1990, 348, 621 . Wragg, J. L.; Chamberlain, J. E.; White, H. W.; Krätschmer, W.; Huffman, D. R. Nature $1990,348,623$

(9) A preliminary account of this work has been presented: Johnson, $R$. D.; Meijer, G.; Bethune, D. S.; Yannoni, C. S. Proceedings of the Materials Research Society, Symposium on Clusters and Cluster Assembled Materials, Special Session on Buckminsterfullerene, Boston, MA, November 29, 1990 (in press).

(10) Carr, H. Y.; Purcell, E. M. Phys. Rev. 1954, 94, 630

(11) Engelsberg, M.; Yannoni, C. S. J. Magn. Reson. 1990, 88, 393.

(12) Pake, G. E. J. Chem. Phys. 1948, 16, 327

(13) Amorphous carbon, 99 atom $\%{ }^{13} \mathrm{C}$, Cambridge Isotope Laboratories, Woburn, MA

(14) Reference deleted in press.

(15) Hahn, E. L. Phys. Rev. 1950, 80, 580 spectrally manifest in amorphous or polycrystalline samples as a powder pattern with features that can appear as a relatively sharp ("Pake") doublet."2 The doublet splitting is proportional to the inverse cube of the internuclear distance and can thus be used to measure the carbon-carbon bond length. ${ }^{16}$ It is important to note that this experiment, like that used to measure the chemical shift anisotropy, ${ }^{5}$ must be done at a temperature sufficiently low that molecular rotation does not average the ${ }^{13} \mathrm{C}-{ }^{13} \mathrm{C}$ dipolar coupling ( $\sim 4 \mathrm{kHz}$ for directly bonded carbons) to zero. ${ }^{17}$

Figure la shows the Fourier transform of the signal obtained from the sample described above in a field of $1.4 \mathrm{~T}\left(15 \mathrm{MHz}{ }^{13} \mathrm{C}\right.$ Larmor frequency) at $77 \mathrm{~K}$ with use of the Carr-Purcell Meiboom-Gill sequence. ${ }^{18}$ The spectrum consists of a very strong center line (cropped for clarity) flanked by a weak pair of doublets. The intensity in the center line is mainly due to ${ }^{13} \mathrm{C}$ spins with no nearest neighbor. ${ }^{16}$ The inner and outer pairs of lines are separated by 3158 and $3596 \mathrm{~Hz}$, respectively, and the intensity of the inner doublet is greater. In the absence of broadening due to nearby ${ }^{13} \mathrm{C}$ spins, the separation of the peaks in the Pake doublet obtained from this pulse sequence is given by ${ }^{11}$

$$
\Delta=3 \gamma^{2} \hbar(1-D) / 4 \pi R_{\mathrm{CC}}{ }^{3}
$$

where $R_{\mathrm{CC}}$ is the intercarbon distance, $\gamma$ is the ${ }^{13} \mathrm{C}$ gyromagnetic ratio, and $D$ is the rf duty factor (the fraction of on-time for the $15 \mathrm{MHz}$ radio frequency field). ${ }^{11}$ Using the method outlined in ref 11 , we measured a duty factor $D=0.134$. The carbon-carbon bond lengths calculated from the splittings using (1) are 1.46 and $1.40 \AA$. These are upper limits since the effect of broadening due to nearby ${ }^{13} \mathrm{C}$ spins is to move the peaks together, thereby decreasing the splitting giving a bond length which is slightly greater than the actual value. ${ }^{16}$ Residual molecular motion could also reduce the dipolar splitting, ${ }^{17}$ again yielding bond lengths that would be too large. In the present case this effect can be neglected since observation of a fully developed chemical shift powder pattern with an overall width of $\sim 3 \mathrm{kHz}$ at $100 \mathrm{~K}^{5}$ suggests that at 77 $\mathrm{K}$ (the temperature used in these experiments) the molecule is static on the dipolar NMR time scale $(\sim 250 \mu \mathrm{s})$.

To assess the effect of spectral broadening due to nearby ${ }^{13} \mathrm{C}$ spins, we have made simulations using various bond lengths and compared them to the experimental spectrum in Figure la. ${ }^{16}$ From such comparisons the two bond lengths obtained are $1.45 \pm 0.015$ and $1.40 \pm 0.015 \AA$. A simulation of the spectrum with use of these values is shown in Figure $1 \mathrm{~b}$. Although the two values of $R_{\mathrm{CC}}$ could be quite close given the estimated uncertainties, the difference in bond lengths must be at least $0.04 \AA$ in order to give a splitting of the magnitude shown in Figure 1a. The simulation shown was made using twice as many $1.45 \AA$ bonds, but the experimental signal-to-noise ratio is not high enough to determine the relative number of long and short bonds. The measured bond lengths are consistent with the values that have been calculated for the truncated icosahedral structure proposed for $\mathrm{C}_{60}{ }^{7}$ For the sake of completeness we also made a simulation, shown in Figure $1 \mathrm{c}$, using bond lengths $(1.451$ and $1.345 \AA$ ) predicted for a truncated dodecahedron. ${ }^{19}$ It is clear that this simulation does not fit experiment so well, thus providing strong support for the truncated icosahedral form.

Carbon-13 enrichment increases the probability of finding clusters of more than two directly bonded ${ }^{13} \mathrm{C}$ atoms. Dipolar spectra from a cluster of three or four bonded ${ }^{13} \mathrm{C}$ atoms are complex, with many lines spread over a frequency range twice the observed doublet splittings. ${ }^{20}$ Since no intensity was detected

(16) Yannoni, C. S. Kendrick, R. D. J. Chem. Phys. 1981, 74, 747 Horne, D.; Kendrick, R. D.; Yannoni, C. S. J. Magn. Reson. 1983, 52, 299.

(17) Gutowsky, H. S.; Pake, G. E. J. Chem. Phys. 1950, 18, 162.

(18) Meiboom, S.; Gill, D. Rev. Sci. Instrum. 1958, 29,688.

(19) Shibuya, T.-I.; Yoshitani, M. Chem. Phys. Lett. 1987, 137, 13

(20) Andrew, E. R.; Bersohn, R. J. Chem. Phys. 1950, 18, 159. Bersohn, R.; Gutowsky, H. S. J. Chem. Phys. 1954, 22, 651. McIntyre, H. M.; Cobb T. B.; Johnson, C. S. Chem. Phys. Lett. 1970, 4, 585. Cobb, T. B.; Johnson, C. S. J. Chem. Phys. 1970, 52, 6224. Eichhoff, Von. U.; Zachmann, H. G. Kolloid-Z. Z. Polym. 1970, 24I, 928. Nicol, A. T. Magnetic Resonance in Colloid and Interface Science; Fraissard, J. P., Resing, H. A., Eds.; D. Reidel Publishing Co.: Holland, 1980; p 207. 
outside the peaks separated by $3596 \mathrm{~Hz}$, isolated pairs of ${ }^{13} \mathrm{C}$ spins appear to predominate for our sample. This is consistent with estimates made assuming that atoms are randomly introduced into the molecules. In particular, for $6 \%$ enrichment, the probabilities for 2,3 , and $4{ }^{13} \mathrm{C}$ atom clusters are approximately in the ratio $100: 10: 1$. We would also not expect the results to be affected significantly by $C_{70}$ since (1) there is much less $C_{70}$ present in the sample and (2) calculations indicate that it has seven different bond lengths. 21

In conclusion, we have measured two carbon-carbon bond lengths in $\mathrm{C}_{60}: 1.45 \pm 0.015$ and $1.40 \pm 0.015 \AA$. This result is consistent with the soccerball (truncated icosahedron) structure proposed for $\mathrm{C}_{60}$. The observation of ${ }^{13} \mathrm{C}-{ }^{13} \mathrm{C}$ dipolar coupling in enriched $\mathrm{C}_{60}$ suggests that it may be possible to explore the mechanism of fullerene assembly with multiple quantum cluster counting. ${ }^{22}$

Acknowledgment. The authors enjoyed stimulating discussions with R. D. Johnson and H. C. Dorn. They are also grateful to R. D. Johnson for solution NMR measurements, M. S. DeVries for a mass spectrometric analysis, and R. D. Kendrick for skillful technical assistance. IBM France provided generous financial support for P.P.B. as an IBM Visiting Scientist.

(21) Rudzinski, J. M.; Slanina, Z. Togasi, M.; Osawa, E. Therm. Acto $1988,125,155$.

(22) Baum, J.; Gleason, K. K.; Pines, A.; Garroway, A. N.; Reimer, J. A. Phys. Rev. Lett. 1986, 56, 1377.

\section{The Infrared Spectrum of Silacyclopropenylidene}

George Vacek, Brenda Thies Colegrove, ${ }^{\dagger}$ and Henry F. Schaefer, III*

Center for Computational Quantum Chemistry University of Georgia, Athens, Georgia 30602

Received October 18, 1990

The laboratory synthesis and subsequent astronomical detection of cyclopropenylidene is a story that owes its success to the fruitful collaboration of experiment and theory. After two decades of theoretical ${ }^{1-8}$ and experimental ${ }^{9-14}$ investigation, Reisenauer, Maier, Riemann, and Hoffmann ${ }^{15}$ identified cyclopropenylidene via matrix isolation. They were aided by the ab initio prediction of its vibrational frequencies and infrared intensities provided by Lee, Bunge, and Schaefer ${ }^{16}$ Shortly thereafter cyclopropenylidene was observed in various interstellar sources, ${ }^{17,18}$ aided by the theoretically determined rotational constants. The silicon-substituted species, silacyclopropenylidene, is a likely candidate for

\footnotetext{
†Present address: Dow Chemical USA, Texas Division, Freeport, TX
} 77541 .

(1) Gleiter, R.; Hoffmann, R. J. Am. Chem. Soc. 1968, 90, 5457

(2) Lathan, W. H.; Radom, L.; Hariharan, P. c.; Hehre, W. J.; Pople, J A. In Topics in Current Chemistry; Springer-Verlag; New York, 1973; Vol. 40 .

(3) Hehre, W. J.; Pople, J. A.; Lathan, W. A.; Radom, L.; Wasserman, E.; Wasserman, Z. R. J. Am. Chem. Soc. 1976, 98, 4378

(4) Lee, C. K.: Li, W. K. J. Mol. Struct, 1977, 38, 253

(5) Kollmar, H. J. Am. Chem. Soc. 1978, 100, 2660

(6) Baird, N. C.; Taylor, K. F. J. Am. Chem. Soc. 1978, 100, 1333 6174 .

(7) Shepard, R.; Banerjee, A.; Simons, J. J. Am. Chem. Soc. 1979, 101

(8) Schoeller, W. W. Tetrahedron Lett. 1980, 2l, 1509.

(9) Jones, W. M.; Stowe, M. E. Tetrahedron Lett. 1964, 3459

(10) Jones, W. M.; Denham, J. M. J. Am. Chem. Soc. 1964, 86, 944

(11) Breslow, R.; Altman, L. J. J. Am. Chem. Soc. 1966, 88, 504.

(12) McGregor, S. D.; Jones, W. M. J. Am. Chem. Soc. 1968, 90, 123

(13) Jones, M. W. Stowe, M. E. Wells, E. E. Lester, E. W. J. Am. Chem.

Soc. $1968,90,1849$

(14) Yoshida, Z. Pure Appl. Chem. 1982, 54, 1059.

(15) Reisenauer, H. P.; Maier, G.: Riemann, A.; Hoffmann, R. W. Angew. Chem. Int. Ed. Engl. 1984, 23, 641.

(16) Lee, T. J.; Bunge, A.; Schaefer, H. F. J. Am. Chem. Soc. 1985, 107, 137

(17) Matthews, H. E.; Irvine, W. M. Astrophys. J. 1985, 298, L61. L63.

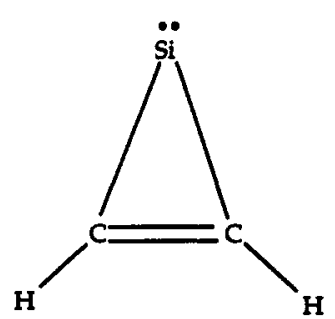

investigation since in recent years there has been significant success in finding silicon analogues of organic molecules. ${ }^{19}$

One might expect the silicon molecule to be more stable than the hydrocarbon due to silicon's propensity for the divalent state. ${ }^{20}$ On the other hand, three-membered rings containing a silicon atom are significantly more strained than the analogous hydrocarbon rings. ${ }^{21}$ There have been two previous theoretical reports on the $\mathrm{SiC}_{2} \mathrm{H}_{2}$ molecular system. Frenking, Remington, and Schaefer ${ }^{22}$ thoroughly surveyed the singlet potential energy surface, locating 15 different isomers. Of these, salicyclopropenylidene was the lowest energy structure. They reported the infrared spectrum at the DZP SCF level of theory. Su, Amos, and Handy ${ }^{23}$ found 16 different triplet isomers of $\mathrm{SiC}_{2} \mathrm{H}_{2}$, but they concluded that the lowest triplet isomer lies $47 \mathrm{kcal} / \mathrm{mol}$ above singlet silacyclopropenylidene. Experimentally, both $\mathrm{Si}^{+}\left({ }^{2} \mathrm{P}\right)$ and $\mathrm{Si}\left({ }^{3} \mathrm{P}\right)$ have been observed to react with acetylene, yielding stable products. ${ }^{24,25}$ Thus far, there is no evidence for a singlet species, although the data suggest that singlet silacyclopropenylidene would be the most stable neutral species. Because there has as yet been no observation of the $\mathrm{SiC}_{2} \mathrm{H}_{2}$ global minimum singlet silacyclopropenylidene despite these indications that it might be a synthesizable species, we have employed ab initio molecular orbital techniques ${ }^{26}$ to predict its molecular properties at much higher levels of theory than have been previously reported.

In this study, we have used two different basis sets (DZP and TZ2P) and several theoretical methods: self-consistent field (SCF), single and double excitation configuration interaction (CISD) and singles and doubles coupled cluster (CCSD). (Studies at the TZ2P CCSD level, however, were slightly beyond our current facilities.) The DZP basis set consisted of a standard Huzinaga-Dunning-Hay ${ }^{27-29}$ contracted double- $\zeta$ basis set supplemented with a set of polarization functions on each atom, i.e., Si(11s7pld/6s4pld), C(9s5pld/4s 2 pld), and H(4slp/2s1p). The polarization function orbital exponents were $\alpha_{\mathrm{d}}(\mathrm{Si})=0.50, \alpha_{\mathrm{d}}(\mathrm{C})$ $=0.75$, and $\alpha_{\mathrm{p}}(\mathrm{H})=0.75$. For the TZ2P basis set on silicon we used McLean and Chandler's ${ }^{30} 6 \mathrm{~s} 5 \mathrm{p}$ contraction of Huzinaga's $12 \mathrm{~s} 9 \mathrm{p}$ primitive Gaussian set augmented by two sets of six Cartesian d-like functions with orbital exponents $\alpha_{\mathrm{d}}(\mathrm{Si})=1.0$, 0.25 . For carbon and hydrogen we used a standard HuzinagaDunning-Hay triple- $\zeta$ basis set and two sets of polarization functions, each with $\alpha_{\mathrm{d}}(\mathrm{C})=1.50$ and 0.375 and $\alpha_{\mathrm{p}}(\mathrm{H})=1.50$ and 0.375 , i.e., $C(10 s 6 \mathrm{p} 2 \mathrm{~d} / 5 \mathrm{~s} 3 \mathrm{p} 2 \mathrm{~d})$ and $\mathrm{H}(4 \mathrm{~s} 2 \mathrm{p} / 3 \mathrm{~s} 2 \mathrm{p})$. The TZ2P CISD wave functions included 120787 configuration state functions (CSFs) for the $C_{2 v}$ equilibrium geometry, and up to

(19) Apeloig, Y. In The Chemistry of Organic Silicon Compounds; Patai, S., Rappoport, Z., Eds.; John Wiley \& Sons Ltd.: New York, 1989; Part 1, p $57 \mathrm{ff}$.

(20) Colegrove, B. T.; Schaefer, H. F. J. Phys. Chem. 1990, 94, 5593

(21) (a) Boatz, J. A.; Gordon, M. S. J. Phys. Chem. 1989, 93, 3025. (b) Grev, R. S.: Schaefer, H. F. J. Am. Chem. Soc, 1987, 109, 6569.

(22) Frenking, G.; Remington, R. B.; Schaefer, H. F. J. Am. Chem. Soc 1986, $108,2169$.

(23) Su, M.-D.; Amos, R. D.; Handy, N. C. J. Am. Chem. Soc. 1990, 112, 1499.

(24) Bohme, D. K ; Wlodek, S. Fox, A. In Rate Coefficients in Astrochemistry; Mollar, T. J., Williams, D. A., Eds.; Astrophysies Space Science Library; Kluwer Academic Publishers: Boston, 1988.

(25) Basu, S. C.; Husain, D. J. Photochem. Photobiol. 1988, A42, 1.

(26) All investigations were performed by using the PSI suite of computer programs, distributed by PSITECH, Inc., Watskinsville, GA

(27) Huzinaga, S. J. Chem. Phys. 1965, 42, 1293

(28) Dunning, T. H. J. Chem. Phys. 1970, 53, 2823

(29) Dunning, T. H.; Hay, P. H. In Modern Theoretical Chemistry

Schaefer, H. F., Ed.; Plenum Press: New York, 1977; Vol. 3, p $1 \mathrm{ff}$

(30) McLean, A. D.; Chandler, G. S. J. Chem. Phys. 1980, 72, 5639. 